\title{
A Comparative Analysis of Japanese, Mexican, and English Marketing Practices: Examining the Influence of Culture on Marketing
}

\author{
Stephanie Nelson ${ }^{1}$ and Travis Smith ${ }^{\#}$ \\ ${ }^{1}$ Episcopal High School, Bellaire, TX, USA \\ \#Advisor
}

ABSTRACT

This research paper examines how the distinct cultures of Japan, Mexico and Great Britain influence companies' respective marketing strategies. These three countries were chosen specifically because of their vast cultural differences and their location on three different continents. First, the paper will compare each country's economic outlook in order to more thoroughly understand each country's market and consumer behavior. Next, each country's culture will be explored through several distinguishing aspects such as religion, family structure, gender roles, society, etc. A summary of each country's consumer behavior and consumer ethics will be given. Next, specific examples of companies that have led successful marketing campaigns in each country will be analyzed in order to determine how they used cross-cultural marketing. The companies used were Coca-Cola for Mexico, Kit-Kat and Louis Vuitton for Japan and Five-Guys for Great Britain. These results can help companies which are trying to launch their products in international markets understand different consumer behavior and markets world-wide.

\section{Economic Overview}

The Mexican economy can be classified as a two-sided developing market economy (World Bank). One part of the economy boasts a trillion-dollar GDP, making it the $15^{\text {th }}$ largest economy in the world, and second largest in Latin America, after Brazil (World Bank). Mexico is also ranked $11^{\text {th }}$ spot in purchasing power parity in the world (World Bank). However, almost $43 \%$ of the Mexican population lives under the poverty line, many living on less than $\$ 5.50$ USD a day (Bajpai; World Bank). Furthermore, Mexico has the second highest degree of socio-economic disparity among the countries forming part of OECD (Bajpai). The Gini index is about 45.4 but has seen a decrease in recent years (Santander). Despite this disparity, Mexico is considered an upper middle-income nation with a nominal GDP per capita of about $\$ 9,946$ USD or $\$ 20,868$ USD (PPP) (World Bank). The average disposable income per capita (PPP) is about $\$ 17,960$ a year. Furthermore, Mexico represents the largest luxury goods market in Latin America due to its growing middle class (Santander).

Japan's economy is known for its highly developed free-market economy. Its GDP is ranked third in the world, worth about 5.08 trillion USD and ranked fourth in purchasing power parity (World Bank). The nominal GDP per capita of Japan is $\$ 42,928$ USD and $\$ 44,585$ in purchasing power parity (World Bank). Japan is considered a highincome nation. Only about $16.5 \%$ of the Japanese population lives under the poverty line, and the Gini index is marked at 29.9 (World Bank). The average annual disposable income per capita (PPP) is $\$ 30,022$ annually (World Bank). In addition, Japan has a well-educated workforce and affluent population, making it one of the largest consumer markets in the world; international trade also contributes significantly to the Japanese economy (Asia link Business). Furthermore, Japan is one of the top three most profitable luxury goods markets in the world.

The economy of England is largely considered a highly developed social market and is known for being one of the most globalized (globalization refers to a country's openness to international trade) in the world (World Bank). Its 
GDP is ranked $5^{\text {th }}$ in the world, worth about 2.829 trillion USD and $10^{\text {th }}$ largest in purchasing power parity (World Bank). The nominal GDP per capita is \$46, 344 USD and its PPP GDP per capita is \$47, 089 (World Bank). The United Kingdom is also considered a high-income nation. The average annual disposable income per capita (PPP) is $\$ 36,553$ (World Bank). About 23\% of the population in the U.K lives under the poverty line, and the Gini index is about 36.3 (World Bank).

\section{Economic Comparison}

In general, Mexico's economy is much less developed than Japan's and the U. K's. In addition, Mexico is still generally considered to be a relatively underdeveloped country. Still, in comparison with other Latin and Central American countries, Mexico is thriving economically. However, the nominal GDP per capita of Japan and the U.K is almost four times that of Mexico, demonstrating the general higher standard of living in both of these countries. The disposable income per capita of Mexico is almost half of both Japan and the U.K. This demonstrates the larger consumer markets available in both Japan and England, since many Mexicans are mostly focused on surviving on a day-to-day basis. Finally, the percent of the population living in poverty in Mexico is double that of the U.K and Japan, further highlighting this issue.

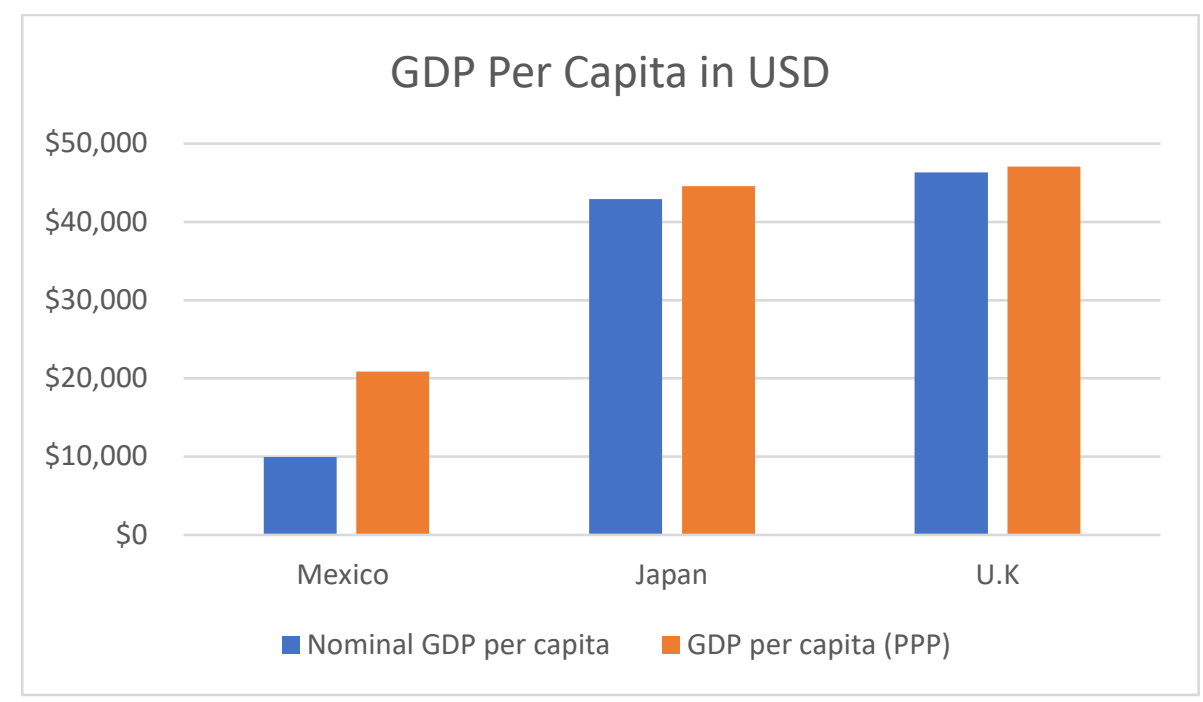

Fig 1

\section{Fig 2}




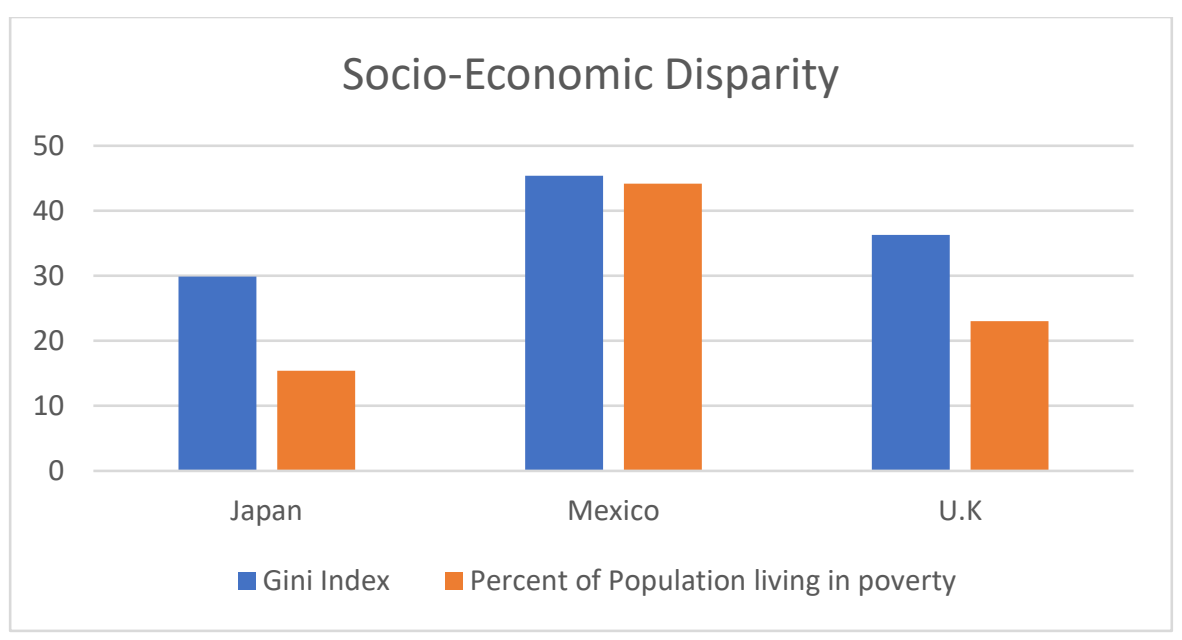

\section{Fig 3}

Gini Index: The Gini coefficient represents the degree of inequality in the distribution of wealth in a country. This coefficient tends to be higher in less developed countries.

\section{Culture}

Mexican culture will be analyzed through the following five criteria: religion, family values, social hierarchies, national culture, and socialization. Religion is by far one of the defining features of Mexican identity. In fact, Mexico represents the second largest Catholic population in the entire world (Rome Reports). About 83\% of Mexicans are Catholic, and another 10\% identify as a part of other Christian denominations. Mexican culture as a whole revolves around religious values of the Catholic church which is deeply infused in the public and day to day language. Important Catholic events are at the center of Mexican tradition, such as weddings, baptisms, and first communions. An important icon of Catholicism in Mexico is "La Virgen de Guadalupe". Her darker skin than those of other depictions of Virgin Mary indicates how Catholicism has evolved to fit a Mesoamerican context. Secondly, family values are one of the most important elements of Mexican society. The Mexican family is built around a sense of community, support and identity. On average, Mexican families are relatively large and have around 3.87 children. In addition, Mexicans feel very responsible to their immediate and extended family and are very conscious of these responsibilities. Furthermore, traditional gender roles are emphasized within families. In fact, Mexicans are very patriarchal, and men commonly have more authority than women. Normally the father is the "jefe de familia" and carries out important decisions. Men also tend to act "macho" and are expected to be masculine and self-reliant. Women are expected to be in charge of the household and raising children. These traditional gender roles are much more prevalent in lower income families and are less emphasized for upper classes. Social hierarchies are another defining aspect of Mexican society. Class differences are extremely distinct and are commonly associated with race; fairer skin most likely tends to make up the upper class. This reflects the historic influence of European colonists and the caste system they established in Mexico. People usually tend to accept the social hierarchy and do not seek to change it. In addition, class defines daily activities and employment opportunities for most people; most Mexicans lie in the lower socioeconomic bracket. More than half of Mexicans work in informal sectors of the economy. Due to the great difference in wealth, labor is much cheaper. It is also significantly harder to change social class than in the United States or Europe. Furthermore, Mexicans are very proud of their country's culture. Mexicans share a common sense of cultural depth, wealth and uniqueness. In fact, Mexicans are very careful to preserve their cultural character. Finally, Mexican culture is defined by being highly sociable. People love to socialize and devote much time to social occasions. Social culture also tends to be highly indulgent.

Japanese culture will be analyzed through the following criteria: religion, family values, professional career, and collectivism. To begin, unlike Western cultures, religion in Japan is rarely preached or regarded as a doctrine. 
Religion in Japan is categorized as a moral code, a way of living that goes hand in hand with Japanese social and cultural values (Cultural Atlas). About $68 \%$ of the Japanese population is Buddhist and about $79.2 \%$ percent believe in Shintoism (Cultural Atlas). These two religions are often combined into one and can be practiced at the same time. Religion is generally considered more cultural than spiritual. In addition, Shinto events are regarded as social aspects of Japanese life (Cultural Atlas). Secondly, Japanese feel a heightened sense of belonging and loyalty to their family as interdependence is emphasized in the collectivist society (Cultural Atlas). Individuals are expected to serve their family's interest before their own. Families often have a "collective face", meaning that the act of one individual impacts the perception of one's family name (Cultural Atlas). Gender roles are also emphasized in Japanese families, which tend to be more patriarchal (Cultural Atlas). Mothers usually devote themselves to domestic duties and raising children (Cultural Atlas). In fact, many Japanese parents are utterly devoted to their children's academic success: they are focused on their children receiving a good education and attending a prestigious university. This places extremely heavy expectations on their children to excel and meet their parents' expectations. As in many Asian countries, Japan has an extremely competitive atmosphere between students. Japanese culture also puts a heavy emphasis on participation and diligence within the workforce. There are many expectations to strive for excellence and perfection. Many Japanese even work to the point of utter exhaustion, in certain cases even resulting in death. Japan is extremely productive and technologically advanced. Many people even sacrifice the idea of starting their own family. In fact, the birth rate of Japan continues to decrease as young people put their careers over starting a family. Finally, Japanese people share a common "island mentality" or form of collectivism within their society (Kanagy). Individuals often see themselves as part of a group, rather than individuals. This leads to a great sense or unspoken obligation of loyalty within groups in exchange for belonging and unity (Kanagy). In fact, Japan is one of the most homogenous societies in the entire world with about $98 \%$ of the population having a Japanese ethnicity, also contributing to this collective identity (Cultural Atlas).

British culture will be analyzed through the following criteria: religion, family, class system, diversity, and individualism. English people are not highly religious. About $25 \%$ of the British population does not practice any religion, with an increasing number of atheists, especially among younger people (Cultural Atlas). Furthermore, about $59.5 \%$ of the British population is Christian, but many do not actively practice (Cultural Atlas). Britain has also experienced an increasing number in Muslim immigrants from the Middle East, with about 5\% of their population being Muslim (Cultural Atlas). Next, the British family is classified as being a nuclear family, excluding extended family. However, the archetypical family is no longer the social expectation, due to increasing numbers of divorces and remarriage. More and more children are being raised in single-parent households. The number of same-sex oriented families has increased $40 \%$ since 2015 . However, family still remains an important part of most individual lives. British families tend to be smaller on average, with approximately 1 to 2 children, so as not to stretch themselves economically. The age at which people have children continues to increase due to an increasingly more individualistic society, especially among the middle class (Cultural Atlas). The gender roles in British culture are not regarded as traditional. British women have almost complete support in participation in the labor force and political office, but income inequality still remains prevalent. However, traditional maternal roles are still expected of women to a certain extent. Next, the class system in the U.K. can be classified as mostly middle class. The middle class leads a comfortable lifestyle and receive a secondary to tertiary education. In addition, British society has become less class conscious. There is also a strong belief in social mobility through hard work (Cultural Atlas). Another major factor of life in the U.K. is how increasingly multicultural it has become in the two most recent decades. For example, the population of London includes three million foreign-born residents. This large percentage of immigration has made the U.K extremely diverse in customs and traditions, especially in larger cities. Finally, the U.K can be categorized as one of the most individualistic countries in Europe, and the world. In individualist societies, people are expected to look after themselves and their immediate family. From an early age, children are taught to be individualists, by thinking for themselves and defining their own identity in the world (Cultural Atlas).

\section{Consumer Behavior and Ethics}


The three main purchasing criteria in Mexico are product quality, practicality and price (Santander). It is important to understand that there is a large gap between rural and urban Mexico in terms of income and spending (Santander). In addition, there is a large north and south divide in terms of consumption (Santander). Northern states and the capital, Mexico City, have been the main attractors of foreign investment, and therefore wages tend to be higher; the south is significantly less developed and remains mainly agricultural (these states are significantly more impoverished) (Santander). In the capital and Northern cities, consumers are also more open to international companies (Santander). Mexican consumers also tend to be among the most brand loyal in the world, seeking to establish a connection with the brand or company. Another factor that is crucial to understanding the Mexican market is that cash is actually the most common payment method in Mexico (Santander). A reported six out of ten Mexicans do not have debit cards; and about $56 \%$ of the population does not have their own bank account (Santander). In addition, in most cases the buyer of most products are the housewives, since they are mostly in charge of running the household. The top two percent of the Mexican income bracket (approximately 24 million people) represent a significant market, especially for the luxury goods (Shofner). Among Latin American countries, Mexico is the most inclined to e-commerce. About $85 \%$ of the population buys one item online annually (Santander). The biggest online retailer is Amazon along with Mercado Libre and Walmart of Mexico, which are mega-chain stores (Santander).

Due to Japan's flourishing technological industry and people prioritizing their careers over family, Japan has more disposable income compared to many Western countries. In fact, Japan has become extremely profitable in global markets. Japanese people tend to be very open to foreign products and are often attracted to specialized items from different countries. It is important to note that the Japanese consumers have shown to prefer quality over quantity consumption (Santander). The value of an item tends to be more important than the price. In fact, Japanese consumers are considered the most demanding customers when it comes to quality (Info Cube). Also, on average, Japanese consumers are more brand oriented, because it is both a social symbol of status and assurance of good quality (Info Cube). This is demonstrated in Japan's significant share of the international luxury goods market. Social media also plays a large factor in consumer decisions. Many Japanese watch reviews of products online, and follow influencers, who influence their purchases to a certain extent. In addition, it is important to understand the homogenous and unique cultural environment of Japan; unlike those in many Western countries, Japanese consumers almost all belong to the same ethnic group. The Japanese Shinto-based culture is completely unique to Japan. Furthermore, this Shinto-culture emphasizes individual's responsibility in society at large, which is a crucial part of consumer behavior and emphasizes Japanese values of respect and politeness (Keillor).

The U. K's consumer behavior can mostly be classified as a mass consumer society. Many British people tend to spend their money on trendy items: in fact, a survey conducted indicated that $55 \%$ of British people are impulse buyers (Peat). Furthermore, the British more and more prone to online shopping (up to $86 \%$ of the population uses the internet everyday), and decisions are increasingly influenced by social media, especially Facebook and Instagram (Santander). In fact, Amazon has had an explosive presence in online shopping in recent years, with almost $90 \%$ of British people shopping on the platform (Word Bank). In addition, British consumers tend to spend a lot of money on the leisure economy and experiences rather than consumer goods. It is also important to understand that Britain is extremely diverse; it is important to target specific regions with certain advertising campaigns (Word Bank). It is important to understand the individuality of the British consumer; the British consumer does not want to be classified as a stereotypical homogenous British consumer, since each area has a specific cultural feel. Britain is also highly urbanized, so urban centers represent larger markets.

\section{Successful Marketing Campaigns}

If you travel to Mexico, the Coca-Cola signs are in everyone's sight. Red trucks, chairs, empty bottles; they are inescapable. Coca-Cola has essentially become a party of a Mexican identity. In fact, Mexico boasts the largest amount of Coke consumed per capita in the world (Tuckman). Coca-Cola has almost $40 \%$ of the soft-drink market share in Mexico, completely dominating the industry (Tuckman). The Coca-Cola company has intently pursued smaller and 
more remote villages around Mexico, especially native American groups (Burke). In fact, in many rural, povertystricken areas of the country, Coke is more accessible and cheaper than clean water (Tuckman). Coca-Cola has pursued the lower-income bracket of Mexican society the most, mainly because they represent the biggest consumer market (Burke). Coca-Cola often sells its drinks with promotions, such as "Buy 2 For One" or "This bottle contains $20 \%$ more". These strategies make the consumers feel as if they are being considered and represented. Furthermore, these communities are also less aware of the negative health effects of the sugary beverage than middle and higher classes. Another aspect of Coca-Cola's marketing strategy is to promote the drink as Mexican, rather than American. By doing this, the company made Coca-Cola seem like a distinctly Mexican product, increasing national pride and feeling toward it. Through this the company demonstrates an understanding of Mexican values of national pride and tries to make the product as relatable as possible. In addition, the company has understood the Mexican values of tradition, often making commercials of people drinking the beverage surrounded by family (Burke). Coca-Cola uses both Mexico's economic outlook and culture to target their specific market.

Unlike many chocolate brands such as Snickers and M\&M, the brand Kit Kat has had immense success in Japan. One of the secrets behind their success was in the changing of its name. The name Kit Kat was translated to "Kitto Katto" in Japanese. The changing of the brand's name was not a coincidence. This name sounds extremely similar to the Japanese phrase "Kitto Katsu," which translates to "you will surely succeed". The strategy has enormously contributed to the brand's success, so much so that it has become an annual tradition for students to be gifted Kit Kat's before their exams as a good omen and for encouragement. The Nestle marketing team has been able to make a connection between their brand and Japanese work culture. School and exams are significantly more competitive in Asian culture than in any Western culture. The pressure placed on students by their parents to do well is immense, creating an atmosphere of stress, a phenomenon commonly known as "stress culture". Aside from understanding the stress culture in Japanese academics, Nestle has further adapted their marketing strategy specifically to Japan. Instead of their normal advertisement of the chocolate bark as a snack on the go, such as in Western countries, they have created specific lines of limited-edition flavors. Nestle has created over three-hundred limited edition flavors such as wasabi and melon. Some are even unique to specific regions in Japan and are only sold in their respective regions. This limited-edition strategy has helped bring a sort of "hype" for the brand, making it stand out among its many competitors.

Another brand that has understood Japanese culture is Louis Vuitton. Louis Vuitton earns half of its global revenue from its sixty boutiques in Japan. In recent years, Japan has been considered the world's largest market for luxury brands, with consumers spending up to $\$ 19$ billion on luxury items annually. In fact, Japan represents the highest per capita spending on luxury items of any country in the world (D’Arpizio). The high demand for luxury items is driven by Japanese culture's emphasis on status and exclusivity. Another reason for this is Japan's grouporiented, collectivistic culture, in which there is almost an unspoken societal pressure to possess luxury brands. In fact, these luxury brands have almost become a mass market. Japanese consumption differs from Western standards of consumption, since women were generally more beauty-focused than women in Western cultures (Paul). In fact, Japanese consumption of luxury goods almost seems like a form of social compulsion. In addition, Japan's large middle class contributes immensely to this phenomenon, due to the higher rate of disposable income (Paul). In addition, by opening individualized stores around the country, Louis Vuitton has attracted many more customers than stores located inside shopping malls. By doing this, Louis Vuitton turned shopping into an exclusive experience, often hiring renown architects such as Jun Aoki to design the façade of their stores (Paul). Through this approach, Louis Vuitton created a new hype in the Japanese market, incorporating new trends and art-influenced concepts into their stores. Furthermore, Louis Vuitton adapted a limited-edition strategy, as exemplified in their infamous 2003 spring/summer collection designed in collaboration with the artist Takashi Murakami (Paul). The limited-edition strategy further increased the brand's hype and aligned with Japanese culture of exclusivity.

The American fast food burger chain Five Guys has successfully broken into the British market, with a total of over one-hundred stores nation-wide (Witts). However, the brand does not spend any of its budget on advertising, so how did it become so successful? The answer to this question is the notion of individuality, so prevalent in Western 
countries. Each burger is customizable with at least fifteen toppings, and less than 1\% of the beef in the U.K meets the company's standards (Witts). This approach contrasts with other fast-food restaurants, which put a lot of money into advertising and less into the product. Furthermore, the customizable burger has been a major hit. British customers seem to love the idea of being able to personalize their burger to their individual wants. This goes hand in hand with the general individualistic culture that is present in the U.K. People think of themselves as unique and having different likes and wants than others. This is a major factor in comparing Japanese and British society. For example, in Japan, most fast-food restaurants have pictures of every food item on the menu. Whatever is pictured is exactly what you will receive. In fact, it is frowned upon or even considered rude to ask to change or add things to your food items. This emphasizes Japan's collectivistic society, in which the individual's needs are given up in exchange for group harmony.

\section{Economic Data Collection and Analysis}

In order to be able to understand the economy of each country, data from the World Bank and Santander Trade was collected. The GDP per capita in U.S. dollars of each country was collected, in order to compare the annual income of the average person in England, Japan and Mexico. The annual income per country was also collected in terms of Purchasing Power Parity, meaning the incomes were all compared in terms of how much they would be in the United States. By using the Purchasing Power Parity, the countries could be compared more adequately. Furthermore, the disposable income per capita was also collected. By comparing the disposable income of the average person, the study could give an overview of the markets that would be most successful in each country. In addition, the degree of socioeconomic disparity was collected. This degree is measured by a coefficient referred to as the Gini-Index. The Giniindex measures the percentage of disparity between different socio-economic groups within a country. The higher this coefficient, the greater the disparage between different groups. This coefficient is essential to understanding the markets available in a country.

\section{Cultural Data Collection and Analysis}

In order to understand the effects of culture on consumer ethics for each country, data was collected from different sectors of society. For Mexico, data was collected on religion, family values, social hierarchies, national culture, and socialization. By collecting specific data from these sectors, an evaluation of the consumer ethics was made. These ethics were then applied to Coca-Cola's successful marketing campaign in Mexico. For Japan, data was collected on religion, family values, professional career, and collectivism. These ethics were then applied to Kit Kat and Louis Vuitton's marketing strategy in Japan. For England, data was collected on religion, family, class system, diversity, and individualism. This data allowed for an evaluation of Five-Guys marketing strategy in England. Although some of these countries' sectors are similar to one another's, others are not. This is because the main components of different countries' cultures differ, and therefore the respective marketing strategies for each country differ.

\section{Conclusion}

This study analyzed the effects of different cultures on consumer markets around the world. In order to successfully market products in an international market, it is crucial to understand the culture of the society. For example, Western countries such as Britain place an emphasis on individualism, while Japan has a collectivistic society. This distinction dramatically changes the marketing strategies needed for each country. In addition, it is important to understand the market of each country, and how profitable a certain brand would be in a certain market. For example, Louis Vuitton's success in Japan is a result of the large market available for luxury goods. Louis Vuitton would not have the same success rate in Mexico, because there is not a large percentage of the population that is able to afford the price of a luxury item. This research paper concludes that brands who have been the most successful are deeply knowledgeable 
of the culture of the country in which they are performing. Brands with a better understanding of a country's culture, and which are more ready to adapt to it, will experience higher success rates than those which do not.

\section{Acknowledgments}

I would like to acknowledge my junior year history teacher, Mr. Smith, for guiding me through this research process. Thank you for your patience and encouragement throughout this process which has allowed me to discover new interests and has reinforced my desire to pursue a career in global business.

\section{References}

Bajpai, Prableen. "Emerging Markets: Analyzing Mexico's GDP." Investopedia. Last modified June $25,2019$. Accessed May 4, 2021. https://www.investopedia.com/articles/investing/090315/emerging-markets-analyzingmexicos-gdp.asp.

“British Culture.” Cultural Atlas. Last modified 2021. https://culturalatlas.sbs.com.au/british-culture/british-culturecore-concepts.

“GDP (Current US\$)- Japan.” Last modified 2019.

https://data.worldbank.org/indicator/NY.GDP.MKTP.CD?locations=JP.

“GDP (Current US\$)- Mexico.” The World Bank. Last modified 2020.

https://data.worldbank.org/indicator/NY.GDP.MKTP.CD?locations=MX.

“GDP (Current US\$)- United Kingdom.” The World Bank. Last modified 2020.

https://data.worldbank.org/indicator/NY.GDP.MKTP.CD?locations=GB.

"Gini index (World Bank Estimate)- Japan.” The World Bank. Last modified 2013.

https://data.worldbank.org/indicator/SI.POV.GINI?locations=JP.

"Gini index (World Bank Estimate)-Mexico." The World Bank. Last modified 2018.

https://data.worldbank.org/indicator/SI.POV.GINI?locations=MX.

“Gini index (World Bank Estimate)- United Kingdom.” Last modified 2017.

https://data.worldbank.org/indicator/SI.POV.GINI?locations=GB.

"How 5 Guys Conquered the UK Burger Market.” Big Hospitality. Last modified September 20, 2019. Accessed May 20, 2021. https://www.bighospitality.co.uk/Article/2019/09/20/How-Five-Guys-conquered-the-UK-burgermarket.

"How to Win the Hearts and Trusts of Japanese Consumers." Info Cubic. Accessed May 20, 2021. https:/www.infocubic.co.jp/en/blog/japan/how-to-win-hearts-trust-japanese-consumers/.

“Japanese Culture.” Cultural Atlas. Accessed May 19, 2021. https://culturalatlas.sbs.com.au/japaneseculture/japanese-culture-core-concepts. 
“Japan's Economy.” Asialink Business. Accessed May 19, 2021. https://asialinkbusiness.com.au/japan/gettingstarted-in-japan/japans-economy?doNothing=1.

Kanagy, Ruthy. "Cultural Values of Japan." Moon. Accessed May 19, 2021. https://www.moon.com/travel/planning/cultural-values-of-japan/.

"Marketing to Japanese Consumers: A How to Guide." WordBank. Accessed May 4, 2021. https://www.wordbank.com/us/blog/international-marketing/marketing-to-japanese-consumers/.

"Mexican Culture." Cultural Atlas. Last modified 2021. https://culturalatlas.sbs.com.au/mexican-culture.

Paul, Justin, and Charlotte Feroul. Louis Vuitton in Japan. N.p., 2017.

Peat, Jack. "Majority of Brittons Are Trend Spenders Survey Finds." Independent. Last modified June $26,2018$. Accessed May 20, 2021. https://www.independent.co.uk/money/britons-trend-spenders-survey-money-uka8417216.html.

"Poverty and Equity Brief: Mexico." The World Bank. Last modified April 2020. https://databank.worldbank.org/data/download/poverty/33EF03BB-9722-4AE2-ABC7AA2972D68AFE/Global_POVEQ_MEX.pdf.

Rao, Tejal. "Big In Japan." New York Times Magazine. Accessed May 18, 2021. https:/www.nytimes.com/interactive/2018/10/24/magazine/candy-kit-kat-japan.html.

"Santander Trade." Mexico: Reaching the Consumer. Accessed May 4, 2021. https://santandertrade.com/en/portal/analyse-markets/mexico/reaching-the-consumers.

Shofner, Kenzie. "Global Marketing Guides: Mexico." United Language Group. Accessed May 4, 2021. https://www.unitedlanguagegroup.com/blog/global-marketing-guide-mexico.

"Top 5 Countries with Highest Number of Catholics." Rome Reports. Last modified August 17, 2019. Accessed May 19, 2021. https:/www.romereports.com/en/2019/08/17/top-5-countries-with-highest-number-of-catholics/.

Tuckman, Joe. "Coca-Cola Country in Southern Mexico." The Guardian. Last modified November 15, 2019. Accessed May 18, 2021. https:/www.theguardian.com/world/2019/nov/15/coca-cola-country-in-southern-mexicophoto-essay. 